\title{
"Burnout" as a result of emotional exhaustion in a profession: sociocultural discourse
}

\author{
Nataliya I. Makarenko $^{\text {1a }}$, Yana I. Chaplinskaya ${ }^{1}$, Svetlana B. Kvesko ${ }^{2}$, Daria P. Shamrova ${ }^{3}$ \\ ${ }^{1}$ Tomsk Polytechnic University, 634050 Lenin Avenue, 30, Tomsk, Russia \\ ${ }^{2}$ Tomsk State University, 634050 Lenin Avenue, 36, Tomsk, Russia \\ ${ }^{3}$ Michigan State University, 220 Trowbridge Rd, East Lansing, MI 48824, USA
}

\begin{abstract}
The object of the research is social and emotional wellbeing of the elderly people. The subject of the research is evaluating social and emotional wellbeing of the elderly people. We set a goal to study social and emotional wellbeing of the aged and to formulate the principles of its evaluating. Besides, people who experience the conflict connected with professional activity are often exposed to emotional and professional burning out. The urgency of the work is that the organization of the aged's activity affords to improve the level of their emotional wellbeing.
\end{abstract}

\section{Introduction}

The population of the Earth is steadily getting older. The older people become, the more they depend on economically and socially active population. The state, social services, certain social workers, family and the public should make more considerable efforts to keep physical and mental health of elderly people, to extent their life, and active longevity. This support deals with not only rendering material security, the health and social care, but organizing leisure of older people will allow them to live last days of their life adequately and fruitfully. Therefore it is important and urgent to evaluate social and emotional wellbeing of older people.

Sociologic researches on social feeling of older people, their part and position in society is also necessary to elaborate the strategy of social policy. The study into the feasibility of the elderly, their social rank, adaptive strategies should promote their emotional wellbeing.

The issue is to find out how emotional and social wellbeing of older people promotes stabilizing the social relations. The aim of this work is to research social and emotional wellbeing of older people of advanced age and to develop its criteria.

Scientific and practical value of the research work is in an opportunity to apply the experience of solving the problem of the elderly's social and emotional wellbeing improvement. Older people face an array of problems. The key problems are poor health, poor functional capabilities and loneliness.

Health consists of two components - physical health or somatic and mental health. Mental health can be characterized as a safety of cognitive abilities, existence or lack of mental diseases symptoms, and also emotional wellbeing. Physical health is directly connected with a self-assessment, with diagnosed diseases, and with a frequency of applying for medical assistance.

Late in life, the violation of cognitive (informative) functions is especially often observed. This is a central performance of cerebral affection. In most cases these determinate variations remain within age norm and do not lead to social alienation, but every tenth elderly person has heavier cognitive deficiency that leads to disability, and then to household independence".

\section{Results and discussion}

In the second half of the XX century a life quality system was formulated because of realizing "insufficiency of population living standard quantitative assessment determined by economic indicators". It was used in medicine as well [1].

In a general sense this system considers living conditions of people and patients (in medicine), in particular, their somatic and mental disorders, the carried-out treatment, peculiarities of microsocial environment, adequate life perception, satisfaction with their own physical and mental state, the real-life situation, environment and so forth.

Subjective and objective criteria of the life quality are pointed out. The first group represents people's own assessment of the life quality. This is an emotional satisfaction with life, health, prosperity, recognition of their own certain level of social wellbeing [2].

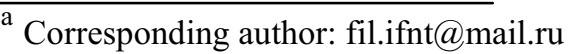


Today the notion "social wellbeing" is widely used in common practice of scientists all over the world in social, psychological, and sociological studies. Researchers import various meanings into this word.

According to the authors, the basic components of the personality subjective wellbeing structure are: satisfaction with his/her financial position, leisure, health and possibility of personal development. All these factors of subjective wellbeing are characteristic for all people, but the level of their significance is different for every person. It is influenced by the age of persons, their state of health, steady or on the contrary unsteady social status [3].

As a rule, people of young age (18-30 years) has high subjective wellbeing and life quality assessment. This indicator averages for the middle-aged persons (30-50 years) and it plummets for persons who are more senior than 50 years [4].

It is possible to distinguish from factors of subjective wellbeing of the efficient age people having families: satisfaction with a social status, material welfare, professional prospects; relationship with administration, with colleagues, with friends; personal and family safety, rest, social environment.

Satisfaction of needs for safety and self-realization can serve as a wellbeing indicator in the material sphere, according to V. A. Khashchenko" [5].

Among significant factors of subjective wellbeing for persons, who through the age and state of health, occur out of habitual situation, there will be feeling of loneliness, uselessness for society. The elderly are not only poorly protected from the viewpoint of a material aspect, with age they start being in need of ongoing physical and moral support.

Many a man cannot do simple things: to move, to dress independently, especially to put on one's shoes as they have to bend over. It is difficult for them to walk upstairs, to use public transport, to wait for their turn in a health centre, to stand in a queue in a shop, to carry products, to cook food, to clear the room, to launder etc. Functional capacities of an organism are gradually failing, and this fact exerts a bad influence on the emotional state.

Narrowing interests late in life are the forced adaptivity directed at saving decreasing organism capabilities. Creative, educated people may not have a recession of mental and creative activity.

The elderly carry over hard the adaptation at the high safety level of the accumulated knowledge and ability to use them.

When elderly persons are invited to solve complex tasks, they feel at a loss as their habitual brainwork standard is broken or can be already declined.

It is possible to draw a conclusion that creative and mental capacities last longer when people are amid familiar surroundings: at favorite work, in the bosom of their family, etc.

The necessity to live late in life in a social facility, among unfamiliar people and service staff, to have the impossibility to apply the forces and express emotions freely influences perniciously the intelligence and creative potential of the person. Therefore, life in a family circle, not in a retirement home, in his/her own house or flat, and, best of all, among loving and understanding people, can sustain life and emotional wellbeing in older age.

The notion of subjective wellbeing of a person appeared in the $60 \mathrm{~s}$ of the XXth century. As S.V. Yaremchuk notes that "during this time the understanding of subjective wellbeing as the wide term reflecting difficult psychological construct was established" [6].

Various theoretical concepts of subjective wellbeing appeared, for instance, Adaptation Level Theory (A. Campbell), Multiple discrepancies theory (A.C. Michalos), a dynamic equilibrium model (B. Headey, A. Wearing), a homeostatic model (R.A. Cummins).

On October 1, 2013, the Global Age Watch index was accepted to determine the life and welfare quality of the elderly population [4]. It includes key components of older people wellbeing: health status, enabling environment, income security, employment and education.

Material welfare is a main factor of subjective wellbeing. At any age material welfare is a basis of social wellbeing. For older people, more often incapable to maintain their economic welfare independently (besides retirement pension), economic welfare is a keystone. It concerns not only maintaining of living standard, but also receiving appropriate medicine care and leisure [7].

Health status is the next factor in well-being hierarchy. For one old person the status of his/her health is a main factor of subjective wellbeing, for others it proceeds from the economic factor, as it is not often the cause, but a consequence. For most of the citizens in Russia, except for those who is provided with the state medicine care free of charge (oncological diseases, diabetes, mental illnesses), the cost of medicine is so high that the elderly should choose which of them should be refused not in extensive health damage and which have to be replaced with cheaper analogues.

The third factor can be an emotional wellbeing. It results from economic wellbeing, of good health status, of good relationship between relatives, of ability to find the niche in limited opportunities of age, any hobby, friends understanding all and likeminded people circle.

Economic wellbeing or ill-being cannot almost be changed in the conditions of the third age. It is easier to lose health, than to recover it, and no tablets and procedures will save from organism aging. As for emotional wellbeing, it depends on many factors.

Firstly, losses of relatives at this age are unavoidable. There is no escaping them anywhere, and an elderly person has to accept unavoidable, after all, eventually $\mathrm{s} /$ he will become a loss himself/herself for someone [8].

Secondly, it is loneliness, even if close people live in the same city. The need to earn money to keep families forces employable young people to spend at work actually all free time except for sleeping.

Thirdly, the facts of our lifetime are as follows: each family lives separately from others; there is no former extensive communication among neighbours. 
Thus, social and psychological factors of subjective wellbeing in the period of the third age are the following: material welfare, state of health, emotional wellbeing as a result of the first two factors and others.

In development of the mankind history, communication activity was the overwhelming prerequisite for education and improving consciousness and language. Communication became the way of formulating personality, as only in the interaction with other people there is socialization of the individual and development of his/her abilities.

The communicative requirement (verbal, nonverbal) is a natural and integral desire of a thinking person. No human community can exist without communication [9].

Communication promotes keeping memory of generations, transferring knowledge, experience, cultural and historical experience.

At least, two subjects can act as participants of communication: there can be two certain people or a group of people, excluding interaction of inanimate objects from the notion of communication

Semantic communication are those where not a thing but the meaning cognized by a person acts as a transmitted message.

Any kinds of semantic communication are interconnected through a personality, through a person as a subject of social communication. For instance, intra personal communication or autocommunication is formed during intellectual development of a person in social environment. It is a mental communication. No matter how the intelligence of a person is developed, $\mathrm{s} /$ he is a public creature. The intellectual development, mental health are impossible without interpersonal communication.

Interpersonal communication is understood as a process of simultaneous interaction of communicants and their influence on each other.

Communication is always the interaction of two or more subjects, persons. It is an exchange of opinions, stories to another, others that saw, heard. Even a gossip, a trivial name of the heard information transfer about acquaintances, is communications too. Ability "to gossip" is not a better feature, but the inevitability of 24 hours stay within the walls of the apartment does not raise life tone of the elderly. The older people need communication process without which they become intellectually deafened, lost, uninteresting and unnecessary to anybody.

The abilities established in character and cultivated at the childhood: sociability, goodwill to the interlocutor, ability to listen to, but not just to speak, ability to remember others, to remind of him/herself, they are communicative abilities which help to keep mental health at late age.

Earlier it was considered that a problem of old men loneliness is possible to improve by resettling them to residential care home where they will be in a group of their contemporaries, and consequently will better understand each other. Gerontoeducation, no matter what form it has, promotes banding people of one generation together as it does not only give them desirable education, but also promotes organizing new communicative relations.

Thus, interpersonal communications gain huge value in saving emotional wellbeing of elderly, already unemployed people. Neither "communication" with the $\mathrm{TV}$, nor upbringing little grandchildren cannot replace interpersonal communication, especially if this communication with the people understanding each other.

Social services and the public face a problem of creating cultural leisure for people of late age. People of advanced age, unemployed and often living alone should not become isolated within their personal world.

Social and emotional wellbeing of older people has its features differed from those that people of working age. The aggravated diseases, the growing physical infirmity, block of mental processes, expectation of coming the end of life, and also sometimes financial problems and poverty make negative impact on selfawareness of wellbeing [6].

Therefore when developing model of social and psychological support of older people it is necessary to pay attention to the identity of the elderly person, his physical capacities and desire to participate in this process.

One of the factors of emotional wellbeing of older people is the psychological comfort which is promoted by social and psychological support not only of native and social workers, but also all not indifferent people.

The identity of everyone is especially individual, and among very old people the identity is not tarnished. By the nature of the character, upbringing, education, the remained intelligence and appetite for life, the identity becomes sometimes much brighter and much more considerable.

The attitude of each person to aging and to the changing state of organism is different. Seriously ill people often keep optimism and external vivacity. Traditionally among old men there are many fans to complain, talk about the diseases, about negative attitude to them of their close people, personnel, passersby, shop assistants, hairdressers, drivers of public transport, passengers and so forth. Often it is perfectly true. But the truth is that, to a large extent individual self-awareness, health are not objective factors of health status, but a subjective self-assessment of the elderly person [8].

One of the ways of psychological and pedagogical support, getting necessary education at any age and helping to build friendly relations is inviting older people (through social welfare bodies) to computer courses.

The first who introduced the term "Professional burnout" was an American psychoanalyst $\mathrm{H}$. Freudenberg, in 1974. This notion means psychological health of a person who has close contact with others. First of all this term characterizes people who worked in psychiatric clinics and crisis centers. But later the definition of this term united all who constantly communicates with people. The term "syndrome of emotional burnout" means any changes in a state of a person and in his/her behavior.

As a result, accumulating negative emotions inside, without deliverance from them, there is a professional 
burning out that can lead to emotionally - energetic exhaustion and burning out of any personal qualities and resources of a person.

Professional burnout is a syndrome which is based on a chronic stress, it leads a working person to emotional and energetic exhaustion. Burning out in most cases appears as a result of accumulating negative emotions inside. As a result, there is no discharge or release from them.

Professionals who according to their work have to communicate often and intensively with different people, not enough acquainted, familiar or unfamiliar. They are managers, heads, consultants, social and health workers, teachers and police officers [9].

Women who are very often broken off between a family and career become an ideal example, as well as they have to prove their professionalism and skills in competition with men.

Such people who easily overcome stress situations are less exposed to emotional burnout. These people are sociable, open-faced, independent and have ability to rely on themselves.

They are able to support optimistic views about themselves and their surroundings.

\section{Conclusion}

Social, economic and medical problems of a person are considerably growing at late age. Unavoidable diseases and infirmity of ageing organism are very dangerous when a personality has to be alone. There is no any necessity to hurry to work, to be responsible for affairs, to be constantly active and ready to do targeted.

Studying the level of social wellbeing of the elderly shows that people at late age often evaluate the quality of their life as bad, very bad, satisfactory and seldom good. Such self-perception negatively influences emotional state of the older people.

In Russia the existing models of social work with the older people not just help to organize individual, independent living, to keep and support physical and mental health of the older people, but partially provide their leisure activities.

Physical and mental ageing of human organism is individual as a character and temperament of people, their mental and creative capacities. On the other hand, the emotional sphere of people at late age considerably changes under the influence of age and diseases. Many old people keep interest to active life, want to be in collective and take an active part in its life.

The ability of the elderly to communicate, their eagerness to be in collective of coevals and like-minded, enthusiastically do common cause slow down their anxiety level. All these things pass off diseases, help to normalize heart function, raise life tone. Interpersonal communications assume great importance in keeping emotional wellbeing of the elderly.

The model of social and emotional wellbeing assessment allow evaluating such characteristics as interest to life of the older testees, peculiarities of their attitude to life (resolution, endurance, moral courage etc.); ability to achieve desired life goals, assurance in their abilities to reach goals; testees' individual selfassessment of their characteristics - physical, psychological and social, psycho-emotional tone, general feeling background.

The research having done by means of this model demonstrates satisfaction of the given group respondents with their social and emotional wellbeing: they spend bigger part of their spare time in collective, do creative work, feel satisfied with their life situation.

Social significance, viability, psychical and physical health, permanent interest contacts, pleasure from communication, reasonable labor activity, physical activity are factors of subjective wellbeing at the late age. A person can have all these if $\mathrm{s} /$ he does creative work, does favourite thing with coevals.

\section{Acknowledgment}

The programme was realized and subsided within the framework of the Programme for enhancing Tomsk Polytechnic University's competitiveness. The results presented herein were obtained with the assistance from Russian Fond.

\section{References}

1. C.E. Izard, The Psychology of Emotions (Emotions, Personality, and Psychotherapy) (Springer,1991)

2. Subjective Wellbeing: An Assessment of Blore J.D.Competing, Theories: Submitted in fulfi lment of the requirements for the degree of Doctor of Philosophy (Deakin University, 2008)

3. P. Brickman, D.T. Campbell, Adaptation Level Theory: A Symposium (New York, 1971)

4. Kvesko R.B., Chaplinskaya Ya.I, Kvesko S.B., Shinn T., International Scientific Symposium «Lifelong Wellbeing In The World» (Tomsk, TPU, 2014)

5. Kvesko R.B., Kvesko S.B., Snitko M.E., Global Science and Innovation: materials of the IV International Scientific Conference (Chicago, USA, 2015)

6. On the trail of the gold standard for subjective wellbeing Cummins R., Social Indicators Research, 179-200 (1995)

7. Journal of Personality and Social Psychology, 57 (4), 731-739 (1989)

8. Multiple discrepancies theory (MDT). Michalos A.C. Social Indicators Research, 16 (4), 347-414 (1985)

9. Subjective Well-being. Proceedings of the Perkins The 9th Australian Conference on Quality of Life (Deakin University. Melbourne, 2008) 